Research Article

\title{
In Situ X-Ray Computed Tomography (CT) Investigation on Localized Deformation and Crack Damage Evolution in a Bimrock by Tracking Rock Blocks
}

\author{
H. J. Meng, ${ }^{1}$ Y. Wang $\left(D^{2}{ }^{2}\right.$ and J. Y. Ren ${ }^{2}$ \\ ${ }^{1}$ Key Laboratory of Neotectonic Movement and Geohazard, Institute of Geomechanics, Chinese Academy of Geological Sciences, \\ Beijing 100081, China \\ ${ }^{2}$ Beijing Key Laboratory of Urban Underground Space Engineering, Department of Civil Engineering, \\ School of Civil \& Resource Engineering, University of Science \& Technology Beijing, Beijing 100083, China
}

Correspondence should be addressed to Y. Wang; good541571889@126.com

Received 9 September 2020; Accepted 5 October 2020; Published 20 October 2020

Academic Editor: Qian Yin

Copyright (c) 2020 H. J. Meng et al. This is an open access article distributed under the Creative Commons Attribution License, which permits unrestricted use, distribution, and reproduction in any medium, provided the original work is properly cited.

\begin{abstract}
Instability of rock mass with block-in-matrix-rocks (bimrocks) often poses a threat to the geological and ecological environment; thus, investigation of the localized deformation and crack damage evolution is critical to predict the bimrock hazards. In this work, triaxial compression testing on block-in-matrix-soils (bimsoils) with a rock block percentage of $40 \%$ (mass ratio) was performed under tomographic monitoring using an original experimental setup specially designed to match the $450 \mathrm{kV}$ industrial x-ray Computerized Tomography (CT) apparatus. A series of 2D CT images were obtained by carrying out CT scanning at key points throughout the test and from different positions in the sample. The physical strain localization phenomenon was well investigated using the proposed Block Tracking Movement (BTM) method to track the trajectory of rock blocks during deformation. The distribution and morphology of cracks are strongly influenced by the interactions between the rock block and the soil matrix including the repeating contact and separation between them that finally results in the macroscopic pattern of cracking. The displacement vector analysis revealed the spatial kinematics of rock blocks during sample deformation and the associated localized band evolution, which was consistent with the macroscopic crack pattern observation. The cracks corresponding to the low-density regions in the bimrock sample further indicate the inhomogeneous pattern of localized deformation. The meso-structural changes and strain localization of the bimrock under triaxial deformation are discussed first by analyzing the rock block movement using x-ray CT data.
\end{abstract}

\section{Introduction}

The phenomenon of strain localization is widely known by many scholars, and it is generally associated with plastic deformation and fracturing in a solid material, especially in the geomaterials, such as the soil and rock material. During the damage and fracture process of the geomaterials, the strain localization phenomenon, viewed as the onset of failure, is one of the most important issues in the field of geomechanics. The formation of landslides, unstable dams, embankments, foundations, and debris flows can be considered to be the macroscopic failure events resulting from the propagation of localized bands. Strain localization is the phenomenon involving multiscales, and it can be observed on the kilometer scale (faults) in nature down to the meter scale (e.g., outcrops and cliffs), and in the laboratory from the millimeter down to the micrometer scale (laboratory sample) (Lenoir et al. 2007). So as to improve the ability to understand and model the strain localization, the initiation and propagation of this phenomenon and the associated crack damage evolution must be experimentally investigated.

In the past, plenty of researches have been devoted to the strain localization in geomaterials. The discussions about the strain localization phenomenon of the geomaterial are investigated for soil (e.g., sand, clay, etc.) at the earliest [1-3]. Bishop and Henkel [4] focused on the relationship between the strain softening behaviors and localized bands. 
Afterwards, many scholars conducted many studies on the formation of strain localization and localized band inclination for loose and dense sand, using direct shear test, triaxial compression test, tensile test, and true triaxial test [2]. Many effects have been done on the deformation characteristics in the localized bands by systematic observation analysis. Experimental investigations have revealed that the mechanism of the strain localization through the use of laser techniques [5], image analysis techniques [6, 7], x-ray radiography [8-13], and x-ray computed tomography [14-19] explained the strain localization theoretically as a bifurcation from homogeneous deformation. From the macroscopic stressstrain experiments, the whole evolution process of the localized band cannot be captured with the naked eye, and the morphology of the localized band can only be observed after the failure of the sample. However, by using some advanced methods (e.g., in situ 3D x-ray diffraction, in situ x-ray microtomography, grain ID-tracking, 3D-volumetric digital image analysis, and spatially resolved neutron diffraction), the strain localization phenomenon can be successfully investigated in real-time during deformation.

After the literature review, almost all the studies about strain localization are focused on soil and rock material; reports on the strain localization for block-in-matrix-rocks (bimrocks) are rarely published. Bimrocks are chaotic units mainly consisting of mixtures of stronger rock blocks with various sizes and weak matrix. When subjected to the internal and external loadings, those individual components always have different mechanical responses. Thus, different mechanical behaviors exist between the bimrock and other homogeneous soil and rock materials. Compared to the general rock and soil material, owing to the complicated interior structure and their components, the physical and mechanical properties of bimrock are much more complex [10-22]. Although many significant experiments proved the existence of localized bands by in situ shear testing [23, 24], in situ large scale horizontal push-shear testing [25], laboratory shear testing [26], laboratory uniaxial testing during static loading [27], laboratory uniaxial test during quasidynamic loading [28], laboratory triaxial testing [29], mesomechanical laboratory testing [30], mesomechanical numerical testing [31], and numerical methods [32], almost all those laboratory experiments are based on the analysis of the macroscopic stress and strain at the scale of the whole sample, whereas mapping of the strain localization is typically only observed after the failure. Fortunately, thanks to the development of the $\mathrm{x}$-ray CT technique, we can observe the evolution process of strain localization in the laboratory.

Application of x-ray CT in bimrock is not among the most common experiments. In our recent experiments on bimrock, CT scanning was used for bimrock with rock block percentage of $40 \%$ under uniaxial compression stress path; the experimental results demonstrated that crack initiated from the rock-soil interface and propagated into soil matrix, and CT value in ROI (region of interest) decreased with the increase of axial deformation [33]. In this work, we continue to study the strain localization behaviors through laboratory experimentation; some of the experimental data are used from the published research; however, a new method was proposed to characterize the damage evolution of bimrock. Unlike in our previous work, recent bimrock experiment was carried out under triaxial compressive stress path. A novel experiment using a self-specially designed loading device in combination with high-energy x-ray CT scanning technique was designed. A simple confining pressure system with independent control of isotropic and deviation components of the applied stress and transparent to x-ray was designed. Rather than focusing on the macroscopic stressstrain characteristics, this paper explores the onset and propagation of strain localization by tracking the spatial kinematics of rock blocks in bimrock using an image analysis technique on the CT images obtained from triaxial deformation. The method proposed for tracking the rock blocks was applied to the results of triaxial compression test, and the displacement fields of bimrock are discussed. This method is a new and effective approach for the investigation of strain localization in bimrock.

\section{Methods}

2.1. Tested Material and Sample Preparation. The tested sample used in the experiment is a mixture of soil matrix with water content of $10 \%$, and rock blocks randomly distributed in the soil matrix. Dynamic compact test was used to prepare the bimrock samples with cylindrical shape (50 $\mathrm{mm}$ diameter $\times 100 \mathrm{~mm}$ height). According to the soil sample preparation standard of GB/T 50123-1999, for the sample diameter studied here, diameter of rock block should be less than $10 \mathrm{~mm}$; the rock block/soil matrix threshold value is determined as $2 \mathrm{~mm}$. The soil matrix belongs to a kind of high-plasticity clay, with its natural density $1.66 \mathrm{~g} / \mathrm{cm}^{3}$, dry density $1.50 \mathrm{~g} / \mathrm{cm}^{3}$, and specific density $\left(G_{s}\right)$ about 2.72. A lot of clay minerals with strong hydrophilic existed in soil matrix; the plastic limit and liquid limit of the soil matrix were about $26.32 \%$ and $63.54 \%$, respectively. The corresponding liquidity index and plasticity index were about 0.05-0.127 and 27.22, respectively. From the water-physical properties analysis, the soil matrix was a kind of typical high and hard plastic clay material. In addition, XRD and SEM experiments were used to determine the mineral content and type in the soil matrix. From the SEM tests, rod-like and irregular quartz grains with grain size about $0.01 \sim 0.03 \mathrm{~mm}$ surrounded by clay minerals can be seen. The XRD tests revealed that the soil matrix has a high percentage of clay mineral, and three kinds of typical clay minerals were found, such as kaolinite, montmorillonite, and illite. The content of them was $26.73 \%, 61.52 \%$, and $6.25 \%$, respectively. Rock blocks used in the study are marble stone with sizes $2 \sim 4 \mathrm{~mm}$ and $6 \sim 8 \mathrm{~mm}$, with the mass ratio of $1: 1$ mixed. Natural density of rock blocks is $2.67 \mathrm{~g} / \mathrm{cm}^{3}$, and the compressive strength is about $94.5 \mathrm{MPa}$ by unconfined compression test.

During the preparation of bimrock samples, rock block percentage was designed as $40 \%$. A certain content of water was added in the mixtures. The optimal water ratio was designed as $10 \%$ according to the relationship between the hammer counts and soil density. Through the compaction test, the optimal hammer count was determined as 18 times for bimrock sample preparation. First, the needs of soil 
matrix and rock blocks for each sample were homogenized and mixed in a mixer. Then, the soil-rock mixtures were placed into a cast iron module with its volume of $50 \mathrm{~mm}$ (diameter) $\times 100 \mathrm{~mm}$ (height). The sample was compacted with three layers; after the compaction of each layer, the top surface of the layer was disturbed in order to make the connectivity between the layers homogeneous. The samples were then sealed with plastic film to prevent water evaporation.

2.2. X-Ray Tomography. X-ray CT as a kind of excellent nondestructive imaging technique can detect the internal characteristics of an object in 2D or 3D quantificationally. According to differences in the atomic composition and density, this method reveals the microscopic structure of the tested material. X-ray CT is first designed for medical imaging; now it has been widely used in the field of material field. Recently, more and more valuable studies have been published using CT method on geosciences (Otani and Obara, 2004; Viggiani et al., 2004). By recording x-ray radiographic images of an object at several different angular positions, this technique achieves the imaging process. Based on either the algebraic algorithms or back projection principle, virtual slices can be reconstructed from these different projections. We can further reconstruct a 3D image of an object by stacking several sequential slices. Adopting the famous Lamber-beer's law, we can obtain the relationship between the intensity of incident radiation and intensity of transmitted radiation, as follows:

$$
I=I_{0} \exp (-u x),
$$

where $\mathrm{I}$ and $\mathrm{I}_{0}$ are the $\mathrm{x}$-ray intensity after and before passing the object of the $\mathrm{x}$-rays, respectively, $u$ is the linear attenuation coefficient, and $x$ is the passing path of the $\mathrm{x}$-rays through the tested object. The images can be reconstructed from the signals in each point, and we call the signal as the CT value. A term of "CT value" is expressed in Hounsfield units and can be defined as follows:

$$
\mathrm{CT}_{\text {value }}=\frac{1000\left(u-u_{w}\right)}{u_{w}},
$$

where $u_{w}$ is the attenuation coefficient of pure water. The calibration usually gives $\mathrm{CT}=-1000$ for air and $\mathrm{CT}=0$ for water. A high CT value usually corresponds to a high density material. Actually, the linear attenuation coefficient is mainly influenced by both the effective atomic number $Z$ and the electron bulk density $\rho$ (Van 2003; Van et al., 2000; Akin and Kovscek, 2003); it can be expressed as follows:

$$
u=\rho\left(\frac{a+b Z^{3.8}}{E^{3.2}}\right)
$$

where $a$ is the Klein-Nishina coefficient, $b$ is a constant, and $E$ is the energy of x-rays.

2.3. Experimental Setup. In this work, a specifically built load device that could be transparent to the $\mathrm{x}$-ray beam is used.
The total system allows conducting the experiments under fully in situ condition. As far as we know, in situ X-ray CT is used here for the first time for the bimrock under triaxial compression. The present work uses a high-energy $\mathrm{x}$-ray CT facility. Here, a high-energy x-ray CT facility was used to perform the CT scanning test; the machine is located at the Institute of High Energy Physics (China). The working principle of the high-energy $\mathrm{x}$-ray computed tomography is the same as the medical computed tomography. For its simplest working principle, from all orientations in a plane, an x-ray fan beam or cone beam is casted at an object, and a 16-bit linear array of detectors is used to measure the intensity attenuation when the $\mathrm{x}$-ray goes through the object, as also seen in Figure 1(a). By rotating the object on a computer-controlled turntable, the $\mathrm{x}$-ray attenuation records are performed equally spaced for $360^{\circ}$ to different angles. A cross-sectional image of the tested object along the plane was then created from the resulting data. Each CT image is called a "slice"; it seems that the object was opened up along a plane, which can be clearly seen. By collecting a stack of contiguous slices, we can build a complete $3 \mathrm{D}$ data model. It is polychromatic for the $\mathrm{x}$-ray source; the source generates $\mathrm{x}$-rays over a continuum of energies from about 30 up to $420 \mathrm{kV}$, which is up to the operating voltage. In the present work, due to the relatively large sample $(\varphi 50 \mathrm{~mm} \times H 100 \mathrm{~mm})$, the sample was conducted via CT scanning at an operating voltage of $400 \mathrm{kV}$ and an electric current of $2.0 \mathrm{~mA}$ conditions. The detailed specifications of the used CT machine are listed in Table 1.

In order to follow in real-time deformation of a sample submitted to classical triaxial test conditions, a test device was designed that was consistent with the requirement of the CT apparatus. The loading device is composed of the reaction frame, displacement measuring system, and load measurement system. The reaction frame of the testing device has to be transparent to $\mathrm{x}$-rays and is therefore made with low attenuation material: a glass fiber reinforced with nylon resin (PA66+GF30) with a density of about $1.38 \mathrm{~g} / \mathrm{cm}^{3}$ is used for the reaction column. Glass fiber with a mass ratio of $30 \%$ is added to the nylon resin, and this material exhibits good performance of heat resistance, strength, and stiffness. When it is subjected to tension stress, the deformation is relatively small. The tensile strength of PA66 + GF30 is about $75.46 \sim 83.3 \mathrm{MPa}$, the yield strength is about $54.88 \mathrm{MPa}$, the compressive strength is about $103.88 \mathrm{MPa}$, and the elasticity modulus is $330 \mathrm{MPa}$. The force measurement system is battery-driven, avoiding wire wrapping during rotation of the rotation device. Figure 1(b) gives the loading device used in the experiment.

The confining pressure is imposed by a specially designed gasbag Hoek cell; the material of the cell is the same as the reaction column, which is transparent to $\mathrm{x}$-rays. The confining pressure can be read from the gas-pressure meter, and the measuring range is $600 \mathrm{kPa}$ with a precision of $0.5 \mathrm{kPa}$. For bimrock, as it is a kind of extreme heterogeneous geological materials, this material contains plenty of random rock-soil interfaces, and the elasticity contrast exists between the soil matrix and rock blocks. During sample deformation, the stress distribution in bimrock is extremely 

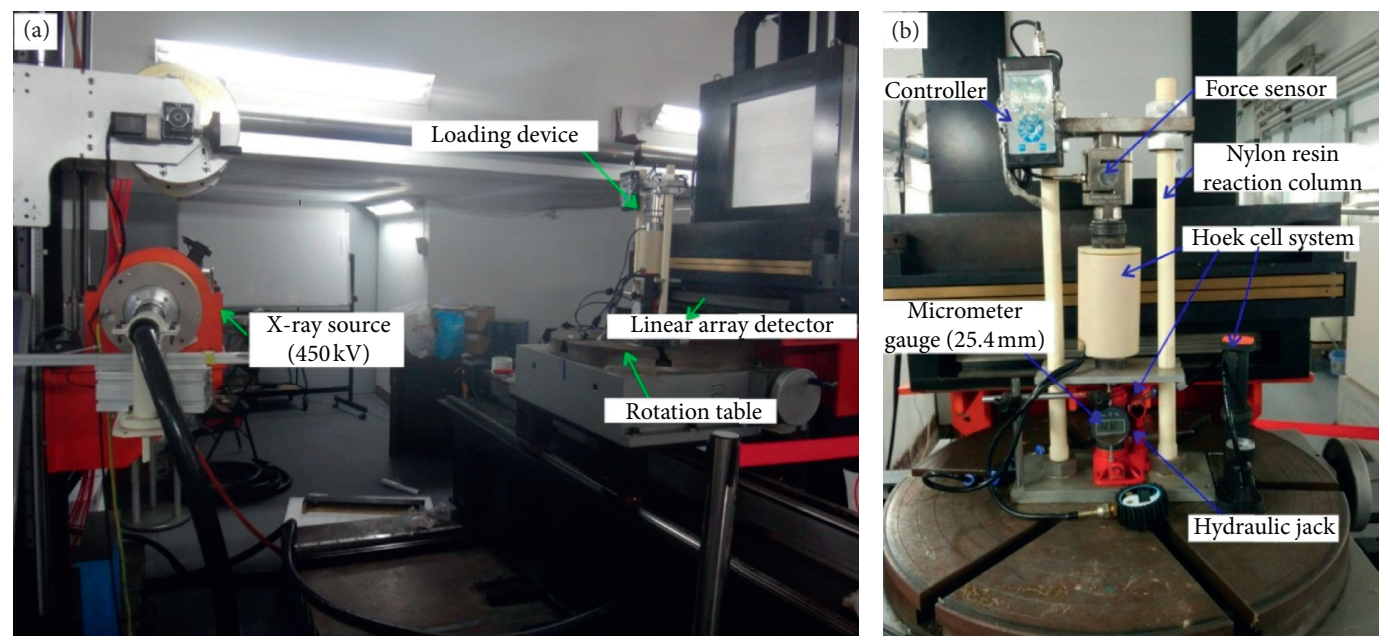

FIgURE 1: The testing devices for bimrock sample (cited from Wang et al. [28]). (a) Industrial CT machine with its voltage of $450 \mathrm{kV}$; (b) the loading device to match the CT device.

TABLE 1: The detailed performance index of the $450 \mathrm{kV}$ industrial $\mathrm{x}$ ray $\mathrm{CT}$ system.

\begin{tabular}{lcc}
\hline Performance parameter of the CT device & Index & Unit \\
\hline Effective scanning diameter & $\Phi 800$ & $\mathrm{~mm}$ \\
Effective scanning height & $\Phi 1000$ & $\mathrm{~mm}$ \\
Maximum scanned weight & 200 & $\mathrm{~kg}$ \\
Penetration thickness for Fe & 50 & $\mathrm{~mm}$ \\
Spatial resolution & $0.07 \times 0.07 \times 0.07$ & $\mathrm{~mm}^{3}$ \\
Perspective of relative sensitivity & 1 & $\%$ \\
Density resolution & 0.1 & $\%$ \\
Minimum scanning thickness & 0.03 & $\mathrm{~mm}$ \\
Fastest scanning time & 1 & $\mathrm{~min}$ \\
Image reconstruction time & 30 & $\mathrm{~s}$ \\
Resolution capacity for crack & $0.05 \times 15$ & $\mathrm{~mm}$ \\
Stomata resolution & $\Phi 0.3$ & $\mathrm{~mm}$ \\
Resolution for inclusion & 0.1 & $\mathrm{~mm}$ \\
Localization accuracy of the workbench & \pm 0.02 & $\mathrm{~mm}$ \\
Accuracy of the turntable & $\pm 5^{\circ}$ & $/ \mathrm{s}$ \\
\hline
\end{tabular}

uneven; the real stress state is that stress acting on every point of the sample surface is equal. Therefore, the gasbag confining pressure subsystem which can provide flexible boundary condition is used to impose the confining pressure in order to realize the equivalent stress boundary for bimrock samples.

2.4. Testing Programme. During the test, first, the loading device was placed on the rotation table of the $450 \mathrm{kV}$ x-ray CT machine. Then, the bimrock sample was placed in the Hoek cell, which is almost completely transparent to $\mathrm{x}$-rays. The confining pressure was applied by the air pump. It should be noted that no drained water was measured during the triaxial tests. The axial stress was applied through a load system with a constant rate of $0.1 \mathrm{kN} /$ step (i.e., every $0.1 \mathrm{kN}$, we recorded the axial deformation), and complete information regarding the axial stress and axial displacement could be recorded. X-ray CT data were obtained along the three central cross sections of the sample; the initial position was $35 \mathrm{~mm}, 50 \mathrm{~mm}$, and $65 \mathrm{~mm}$, respectively, from top of the sample, as shown in Figure 2. For each CT slice, a complete scan was obtained by recording 3600 measurements projects at different angles equally $360^{\circ}$; this took about $1 \mathrm{~min}$. After CT scanning, 2 min was used to conduct real-time reconstruction for the original CT data. Therefore, a section was recorded in approximately $3 \mathrm{~min}$. After completing CT scanning, the linear array detector went down $15 \mathrm{~mm}$, and starting on the next CT scanning, there were 3600 projects again. A total of three CT sections were obtained for each loading stage. In our research, six loading stages were performed for the bimrock sample with a RBP of $40 \%$; thus, we obtained 648000 projects, and this took about $90 \mathrm{~min}$ for the experiment. The data consist of radiological densities for each voxel of this cross section that can be visualized as gray scale image on a grid where each pixel is indexed to the Hounsfield value. The gray scale has a dynamic which is fitted to the range of crack variations inside the sample. The variation of crack inside the sample is computed from the variation of radiological density. When damage occurs in the bimrock sample, the color is black at the position of cracks, as shown in Figure 3.

Figure 3 plots the typical stress-strain curve and the designed scanning points in the experiment. We tested the sample until a maximum axial strain of $8 \%$. Six loading stages were performed with $\mathrm{x}$-ray CT scanning, and the corresponding strain was designed as $0,1.5 \%, 3 \%, 4 \%, 6 \%$, and $8 \%$, respectively. In the practical operation, the axial strain was $0,1.756 \%, 3.106 \%, 4.424 \%, 6.649 \%$, and $8.042 \%$, respectively. When conducting CT scanning, the axial loading was stopped to avoid the movement of the sample due to the loading. After the CT scanning, the axial loading started again with the same loading rate. It should be noted that stress relaxation phenomenon occurs at each step of the scanning process because the axial displacement is fixed during CT scanning. As the stress drop owing to stress relaxation is relatively small, this part was not drawn in the stress-strain curve. 


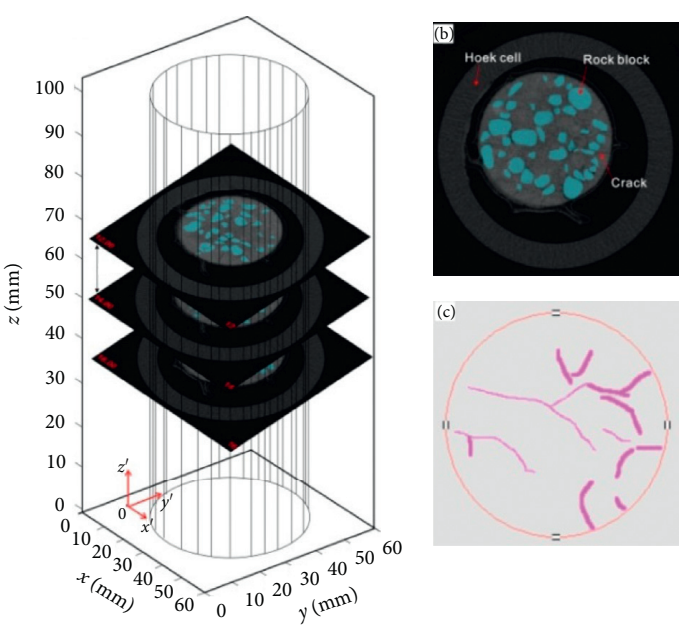

(a)

FIgURE 2: The sample grayscale image data is a bimrock sample. (a) BMP image stack; (b) extraction of the 28th layer of CT; (c) extraction of CT slice cracks.

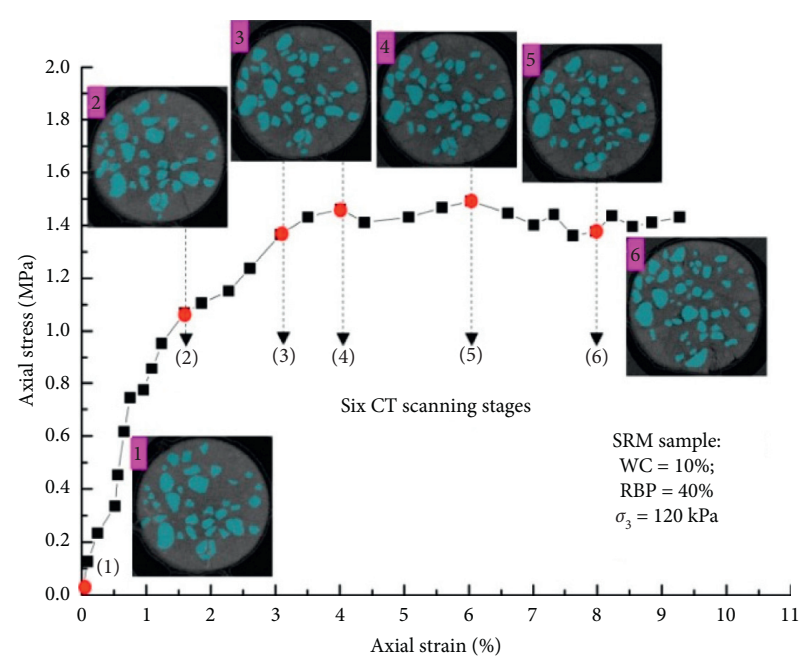

FIGURE 3: Drawing the axial stress-strain curve of the studied bimrock specimen, and selecting 6 key points for CT scanning.

2.5. Image Analysis. To extract the rock block, crack, and realize the rock block ID tracking for the CT images at different loading stages, a method called Block Tracking Displacement (BTD) was proposed. The basic purpose of this method is to track the rock block in bimrock sample and analyze the displacement vector during triaxial deformation. The CT images are 16-bit digital images composed of the socalled "CT value," which is the preliminary output, presented in monotonic dark shades for low CT values and light shades for high CT values, with 256 possible variations. In our $\mathrm{x}$-ray CT apparatus, the CT image is constructed by $1024 \times 1024$ pixels, the thickness of $\mathrm{x}$-ray attenuation. The voxel is $0.07 \mathrm{~mm} \times 0.07 \mathrm{~mm} \times 0.3 \mathrm{~mm}$ for images with a $50 \mathrm{~mm}$ diameter sample cross section. A typical histogram is shown in Figure 4(b), with a peak and a trough on the curve, one representing the rock blocks and the other representing the cracks. In addition, the steady portion on the curve represents the soil matrix.
As shown in Figure 4(b), it plots the changes of gray value (or Hounsfield value) along the profile line (Figure 4(a)). From the variation of $\mathrm{H}$ value, the $\mathrm{H}$ value can be divided into three intervals for rock blocks, soil matrix, and crack, respectively. The rock block and crack can be extracted from the original CT images based on the difference of CT value. A method called a region growing method has been attempted to identify the rock blocks, soil matrix, and crack, individually by a trinarization technique. From the trinarized images, areas of the rock blocks, the soil matrix, and the crack in the local two-dimensional scanning domain have been quantified by counting the number of voxels which occupies each material multiplied by the area of the unit voxel [34-37]. The method can be summarized as follows:

(1) In the region growing method, one voxel, representing one material, is firstly chosen. We sample the gray values for rock block, crack, and soil matrix as much as possible and calculate the average and dispersion for the rock block, $\mu_{\text {block }}$ and $\sigma_{\text {block }}$, soil matrix, $\mu_{\text {soil }}$ and $\sigma_{\text {soil }}$, and crack, $\mu_{\text {crack }}$ and $\sigma_{\text {crack. }}$.

(2) We determine the tolerance of the rock block phase and crack phase, $\mathrm{Tr}$ and $\mathrm{Tc}$, respectively. The gray values of each phase are assumed to comply with normally distribution; determine the domain of each phase between the two values, $\bar{x}_{i} \pm 2 \sigma_{i}(i=r, s, c)$.

(3) The adjacent voxels with similar gray values to the original voxel are assimilated into the same medium. Subsequently, the same procedure is done for the newly assimilated voxels; i.e., the adjacent voxels of the newly assimilated voxels are assimilated into the same phase if the gray values are similar to the original one. Repeating this procedure eventually leads to the formation of one cluster composed of voxels with similar gray values $[38,39]$. Starting from the voxels with the average gray value of each phase, assimilate the adjacent voxels with gray values greater than tolerances value into the each medium. Repeat this procedure for the newly assimilated voxels until no voxels are assimilated. The rock blocks and cracks by the region growing method are shown in Figures 5 and 6, respectively.

(4) After segmenting the rock blocks from the soil matrix, edge detection algorithms were used to determine the boundary of rock blocks; then, the spatial position of each rock block was determined according to the centroid coordinates. The displacement vector of rock blocks at different deformation can be calculated. Figure 7 shows the edge detection result of rock blocks. In order to better interpret the strain localization phenomena, the detection results were overlapped on the original data.

\section{Experimental Results}

3.1. Rock Block ID Tracking. Due to the differential deformation that occurs at rock-soil interfaces, a series of nonlinear behaviors of rock block rotation, movement, and 

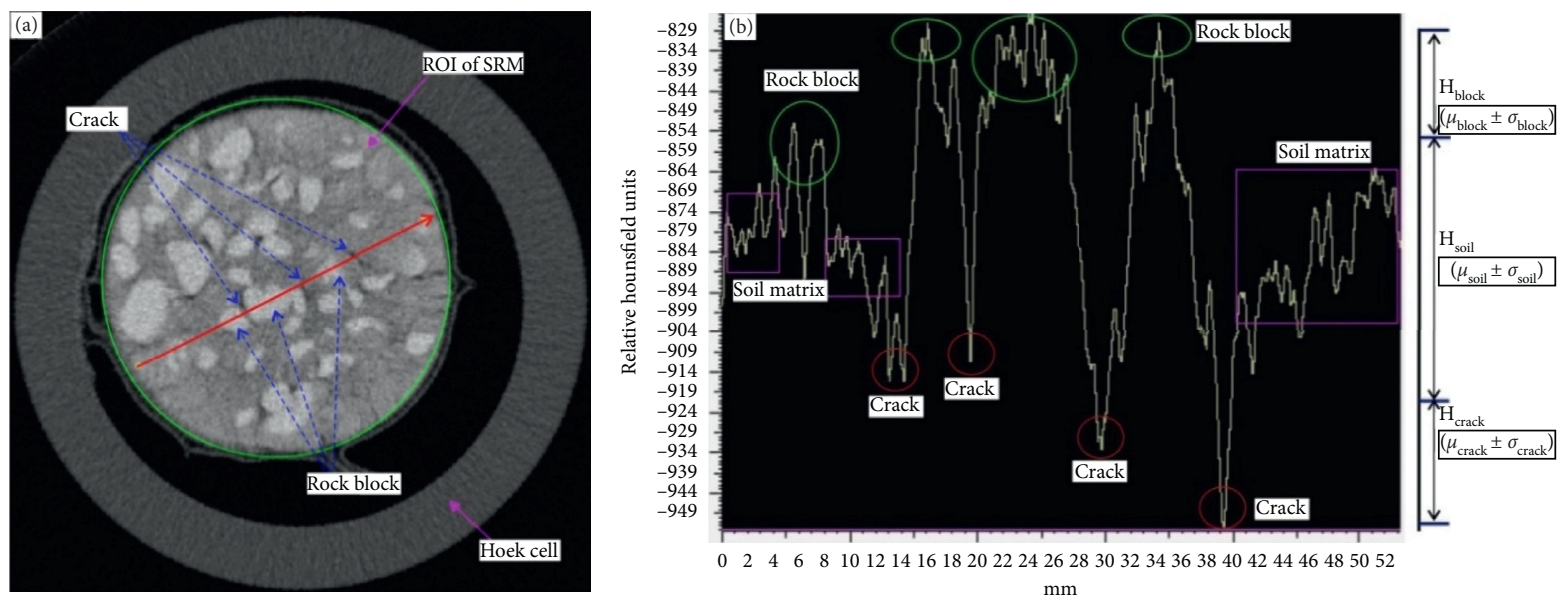

FIGURE 4: Illustration of the method to extract the cracks and rock blocks in CT image. (a) Cross-sectional slice (16-bit) and (b) gray level histogram
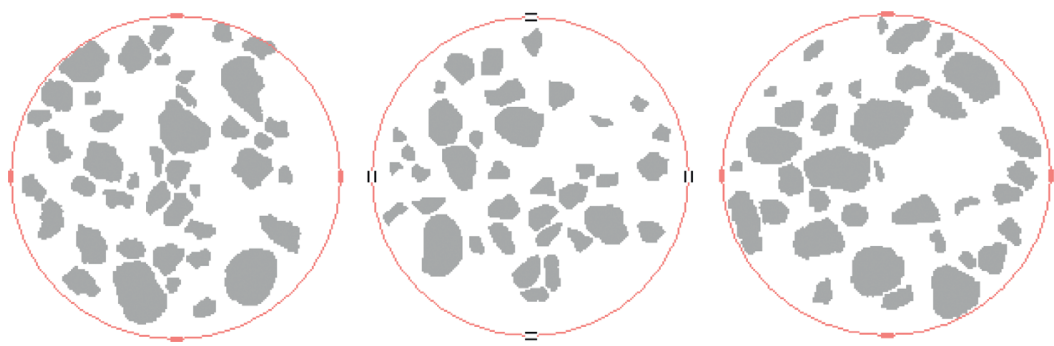

(a)
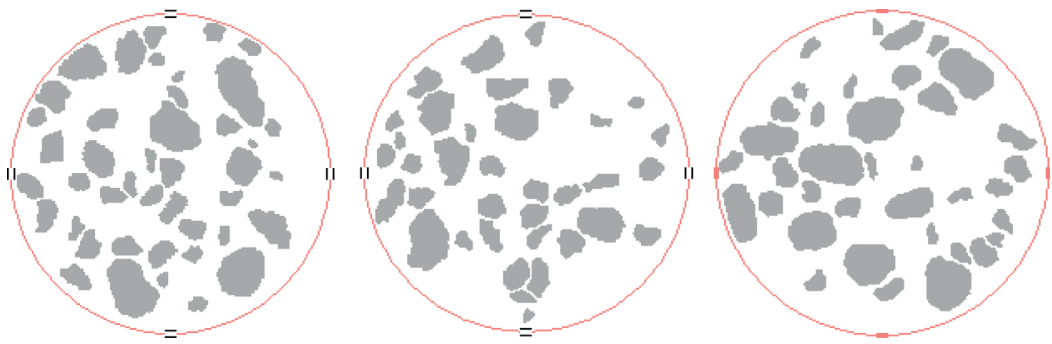

(b)
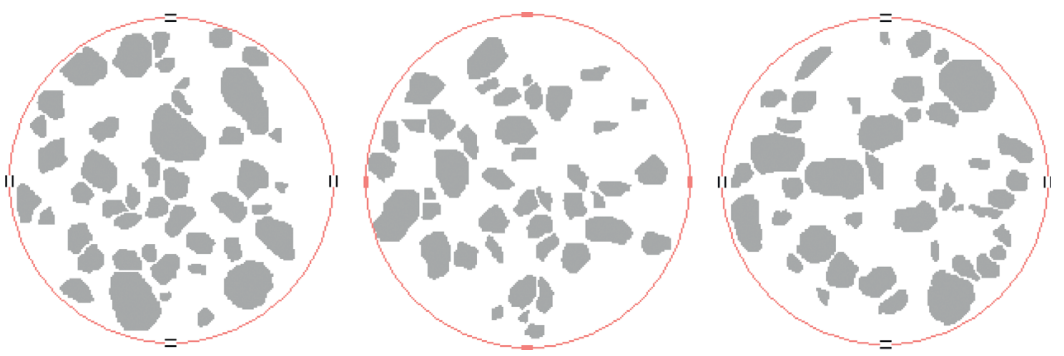

(c)
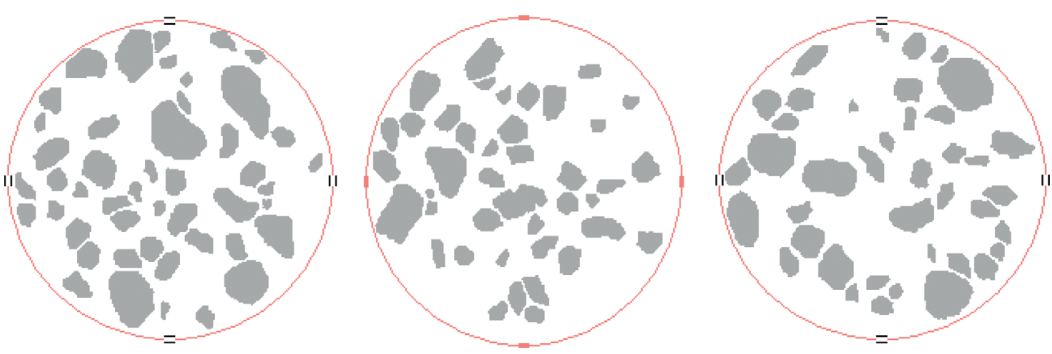

(d)

FIgURE 5: Continued. 

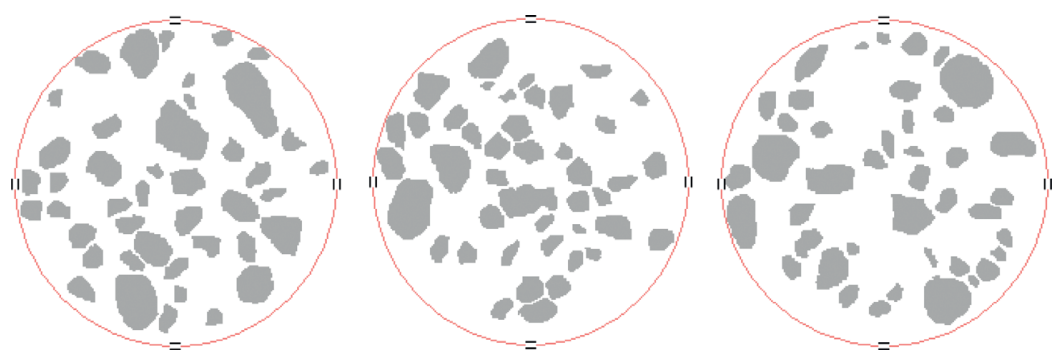

(e)
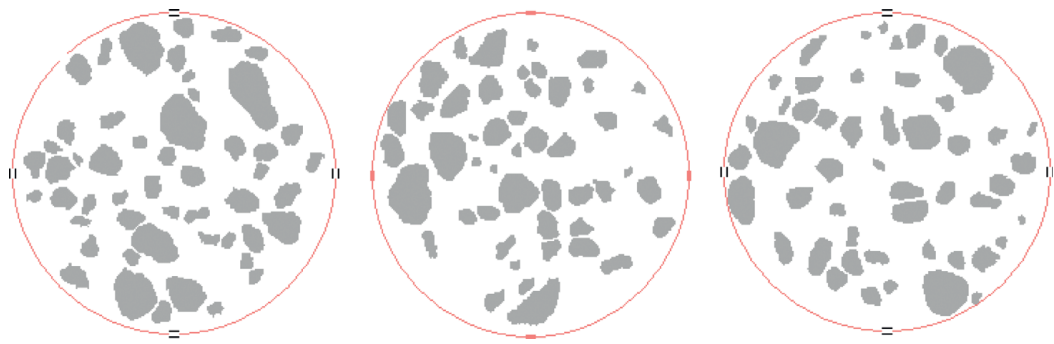

(f)

Figure 5: Rock block extraction from the CT images at different deformation stages. (a) $\varepsilon=0 \%$. (b) $\varepsilon=1.756 \%$. (c) $\varepsilon=3.106 \%$. (d) $\varepsilon=4.427 \%$. (e) $\varepsilon=6.649 \%$. (f) $\varepsilon=8.059 \%$.

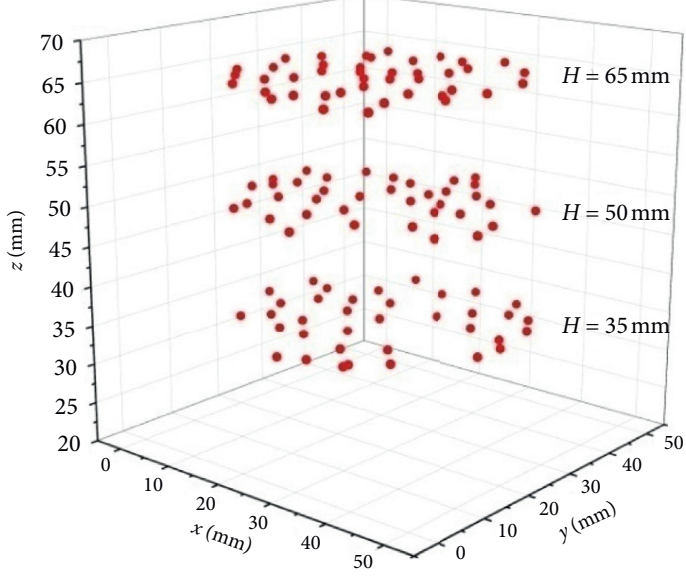

(a)

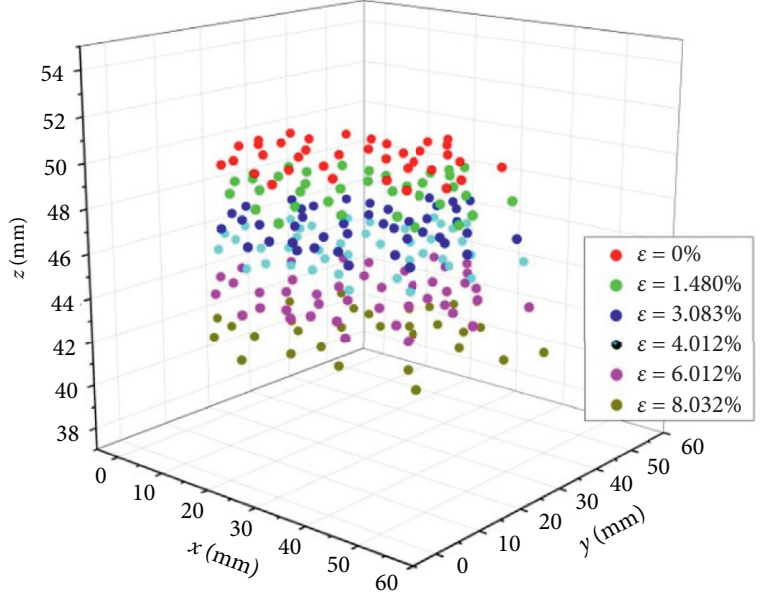

(c)

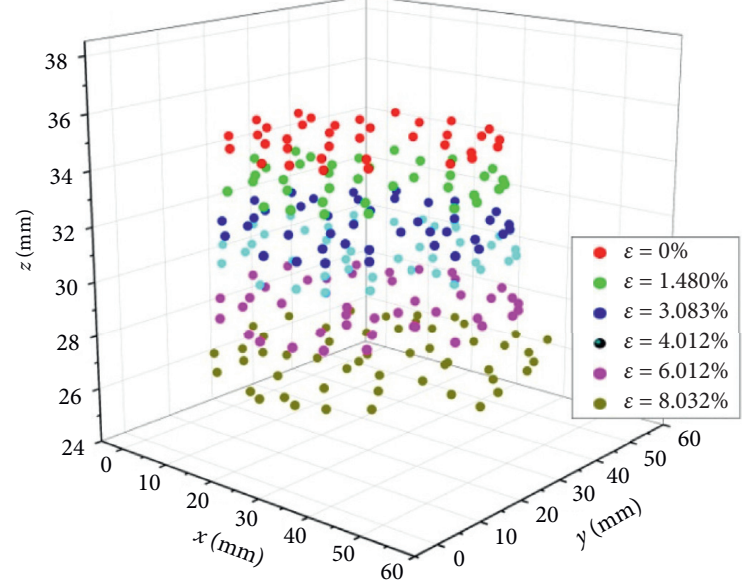

(b)

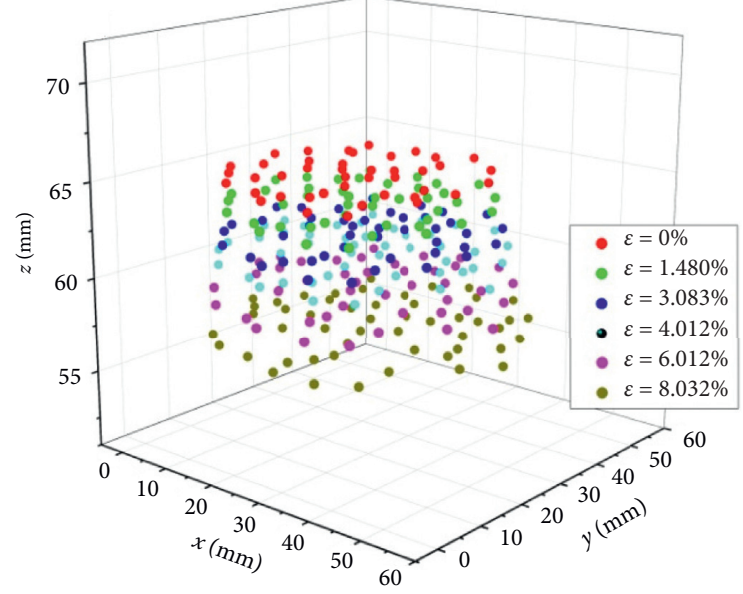

(d)

FIGURE 6: Spatial positions of rock blocks during deformation, for the three x-ray CT scanned sections. 

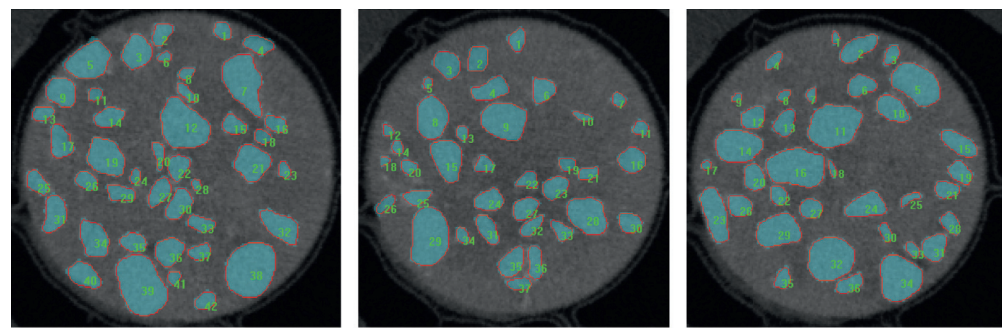

(a)
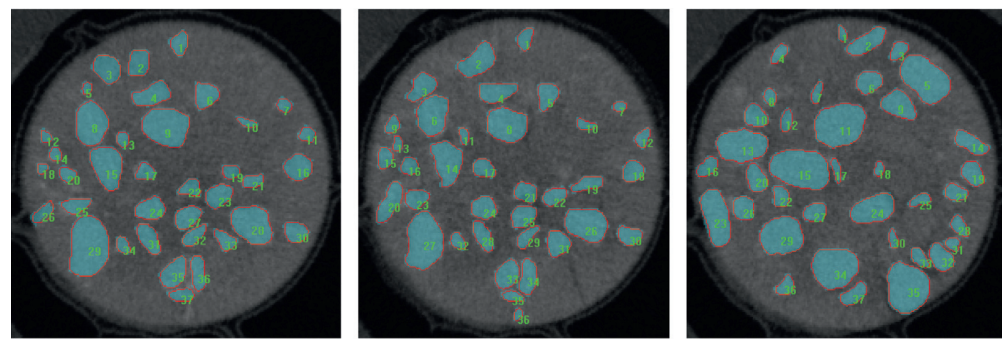

(b)
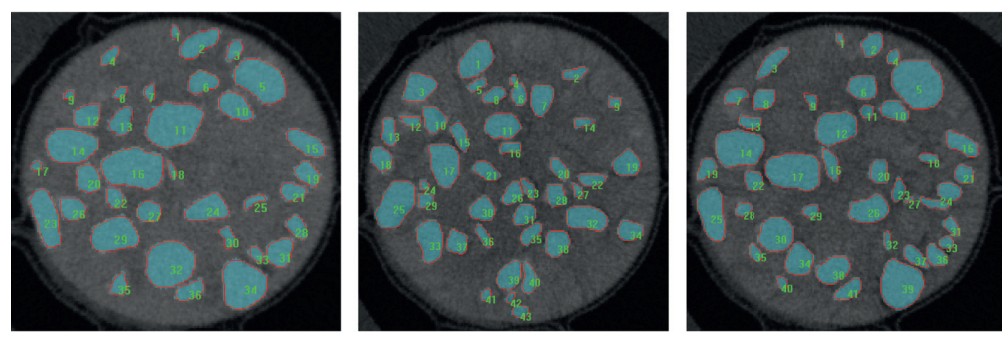

(c)
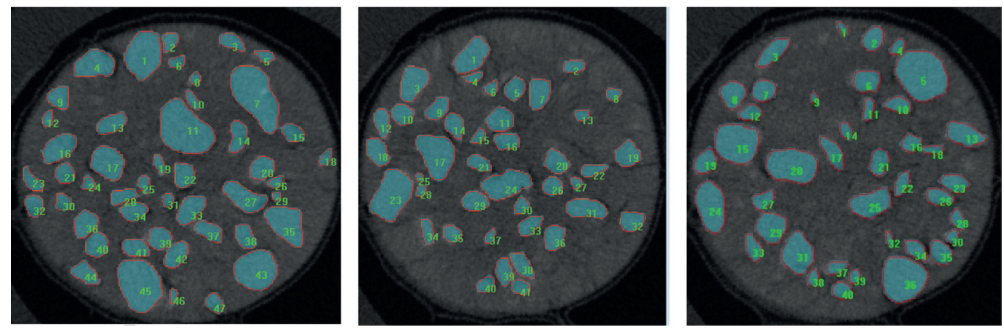

(d)
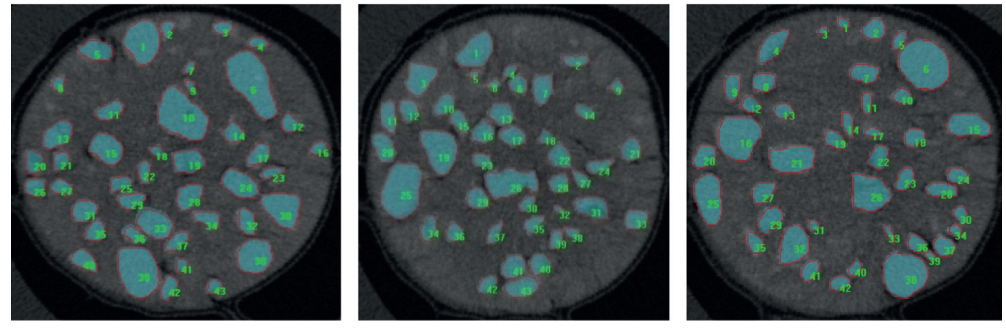

(e)
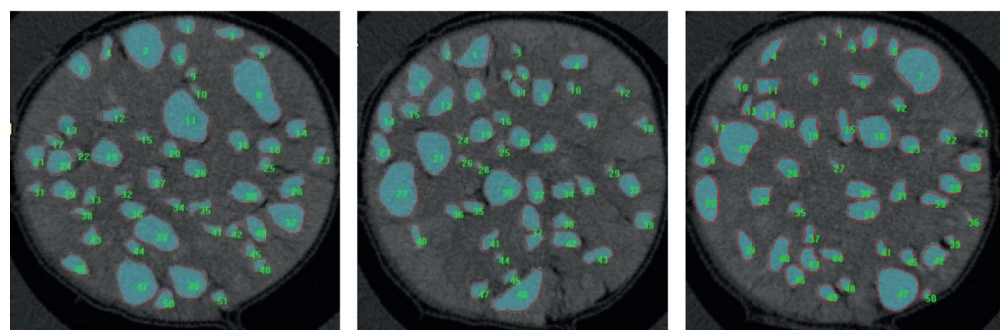

(f)

FIGURE 7: Edge detection of rock blocks in CT images (the edge detection result was plotted on the original CT images). (a) $\varepsilon=0 \%$. (b) $\varepsilon=1.756 \%$. (c) $\varepsilon=3.106 \%$. (d) $\varepsilon=4.427 \%$. (e) $\varepsilon=6.649 \%$. (f) $\varepsilon=8.059 \%$. 
translation can lead to the development of localized bands. In this section, the changes of the spatial positions of rock blocks in bimrock are discussed using the proposed method of Block Tracking Movement (BTM). The initial positions of all the blocks transmitted by $\mathrm{x}$-rays are plotted in Figure 6(a). The number of rock blocks in the three sections is 42,37 , and 36 , respectively. The initial positions are $35 \mathrm{~mm}, 50 \mathrm{~mm}$, and $65 \mathrm{~mm}$, respectively. Because under compression the height of the sample changes, therefore the scanning position and interval are variable and not constant at each CT scanning stage. With the decrease of sample height, the scanning interval change is smaller, and this can be determined from the total variation of the sample height. To do so, it can ensure the same position of every CT scanning at a different loading stage as much as possible. Figures 6(b) 6(d) plot the spatial position of rock blocks at axial strains of $0 \%, 1.480 \%$, $3.083 \%, 4.012 \%, 6.012 \%$, and $8.032 \%$, respectively, from the three positions. It can be seen that the movement of rock blocks becomes severe with the increase of axial deformation. Especially at the bottom of the sample, movement of rock blocks is much more serious than at other parts of the sample. These results indicate that localized bands gradually form with increasing deformation. Due to the formation of localized bands, the volume of the sample becomes larger accordingly. Due to the existence of rock blocks in bimrock, non-linear movement, such as rotation or translation, aggravates the strain localization phenomenon. Through the statistical analysis of the number of rock blocks at different axial strains, we can also find that the number of rock blocks is not the same even though scanned at the same position. During deformation, interactions between the rock block and soil matrix lead to the disappearance of the rock blocks and the appearance of new rock blocks in the specified CT scanning sections. The number of rock blocks in the bimrock sample under deformation is shown in Figure 8.

3.2. Displacement Vector Analysis. The positions of the rock blocks can be tracked from the initial point to their position after vertical loading, and then the displacement vectors based on the movement of rock blocks are computed. Figure 9 plots the displacement vector of the rock block during triaxial deformation, and from the distribution of the displacement vector, the progressive localized deformation can be clearly seen. In Figure 9(a), when the axial strain is from $0 \%$ to $1.480 \%$, movement of rock blocks takes the priority of vertical movement and is parallel to the axial direction. In Figure 9(b), when the axial strain is from $1.480 \%$ to $3.083 \%$, the stress-strain curve records the compaction stage to the strain hardening onset, movement of the rock block begins in the lateral direction, and the lateral expansion begins at this stage. In Figures 9(c) 9(e), when the axial strain is from $1.480 \%$ to $8.032 \%$, the strain localization phenomenon becomes obvious with increasing deformation. Expansion of the sample is the most distinct when the axial strain reaches $8.032 \%$. Figure 9(f) shows the strain localization of the sample from the state of unloading to failure. Compared with its initial state, the rock blocks move in two lateral directions when the axial deformation reaches the maximum, and the apparent localized bands can be seen in Figure 9(f). From the evolution of localized bands in the bimrock sample, the inhomogeneous localized regions propagate with the increase of sample deformation. In addition, the localized bands are located at the rock block centralized zones, and the distribution of the rock block strongly influences the distribution and morphology of localized bands.

Because the rock-soil interfaces are the weakest part in bimrock, the evolution of localized bands is often accompanied by the occurrence of cracks in the low-density region. Cracks in the bimrock sample are the reflection of stress distribution heterogeneity and the associated strain localization. Figure 10 plots the crack morphology in the bimrock sample. We can see that the number of cracks increases with increasing deformation; this result is consistent with the evolution of localized bands. When the axial strain equals $1.480 \%$, a small number of cracks can be observed in CT images marked with lower density region. Two kinds of cracks coexist in the bimrock sample: one kind is the main crack, which propagates into the soil matrix; the other kind is called a secondary crack, which develops around rock blocks. The morphology of the crack is close to the distribution and shape of rock blocks. In addition, interlocking phenomenon occurs around rock blocks, the already existing cracks close due to the movement of rock block. The result implies that the rock block is the main factor controlling the crack geometry distribution, and the associated deformation of the bimrock. When the strain exceeds $1.480 \%$, a few cracks initiate from the rock-soil interface with low-density region; when the stress exceeds $3.106 \%$, the number of cracks increases sharply, and the main crack propagates into the soil matrix, bypassing rock blocks. The strain localization becomes obvious at the strain hardening stage, and a large scaled shearing band forms. It can be inferred that the shearing band is discontinuous and bypasses rock blocks from the crack distribution. According to the crack distribution in Figure 10, cracking in the bimrock is attributed to the interface cracking mechanism, stress concentration, and the deformation incompatibility leads to the cracking. We can see that cracking first occurs at block tips, the adjacent block makes the soil body around them rotate in the opposite direction, and the rotation torque results in the cracking of the soil. In addition, the separation phenomena of the soil and the rock block can be clearly observed. During triaxial deformation, rotation torque forms at rock block tips and the rock-soil interface, owing to the incompatible deformation between the rock block and soil matrix, and large porosity forms.

3.3. Macroscopic Failure Morphology Analysis. Failure morphology of bimrock is strongly controlled by the rock block content. The macroscopic failure pattern of rock is the external reflection of its internal damage evolution [40, 41]. Wang et al. [22] pointed out that the failure process of bimrock is the rearrangement of soil and rock block particles. During the process, the rock blocks and soil matrix bear axial loading in their unique ways. Rock block 


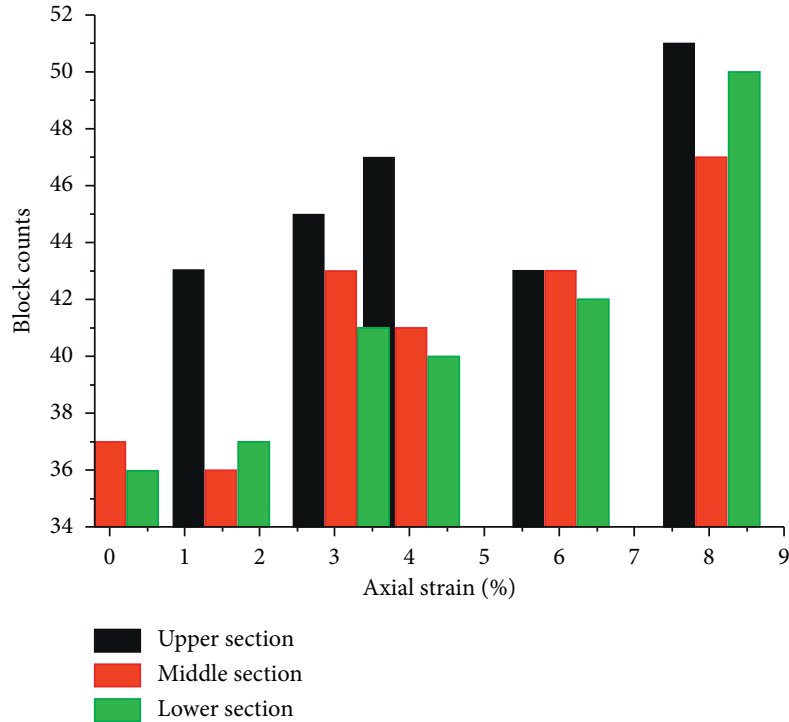

(a)

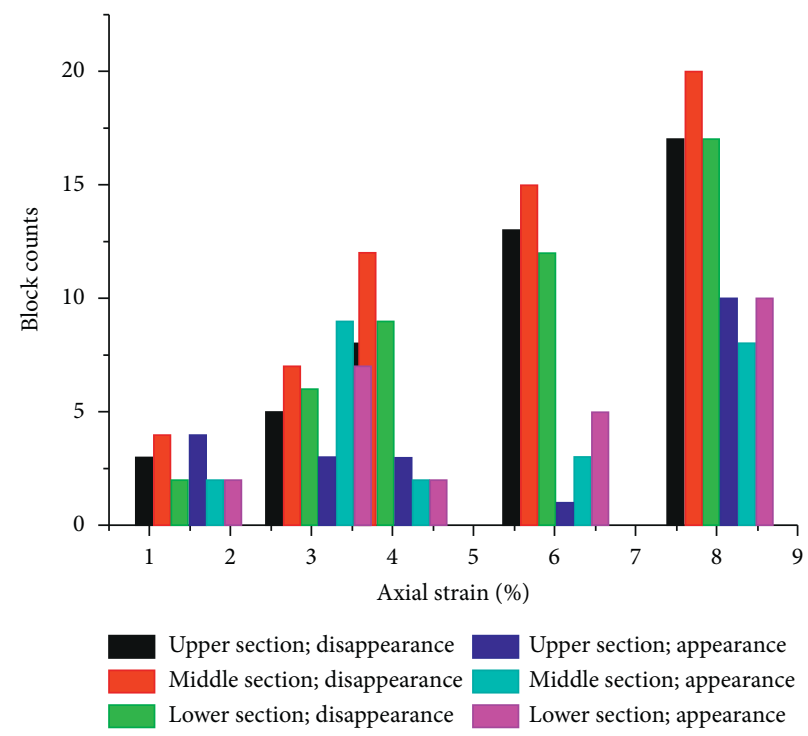

(b)

FiguRE 8: Statistical number of rock blocks in bimrock under deformation for the three scanned sections. (a) Total number of rock blocks at different axial strains; (b) number change of rock block at different axial strains.

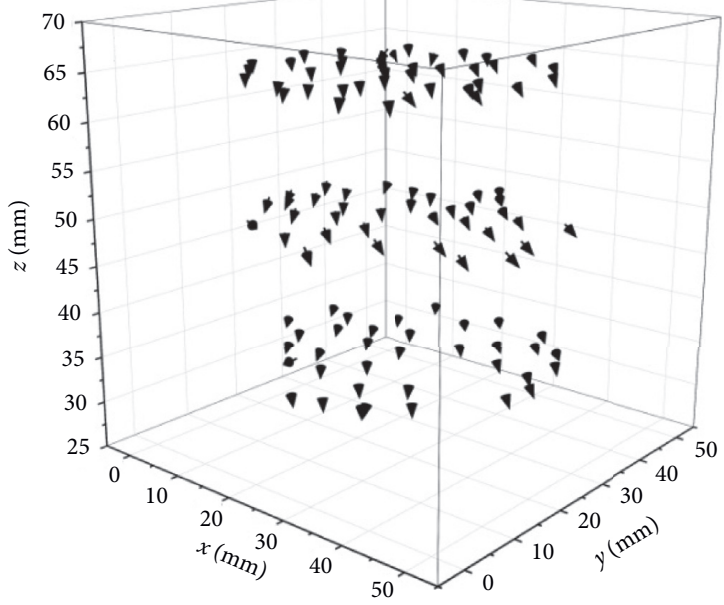

(a)

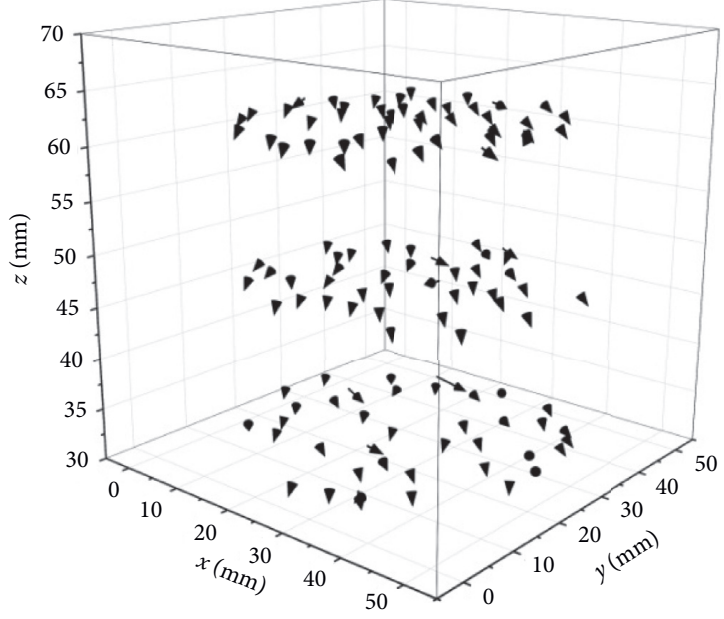

(c)

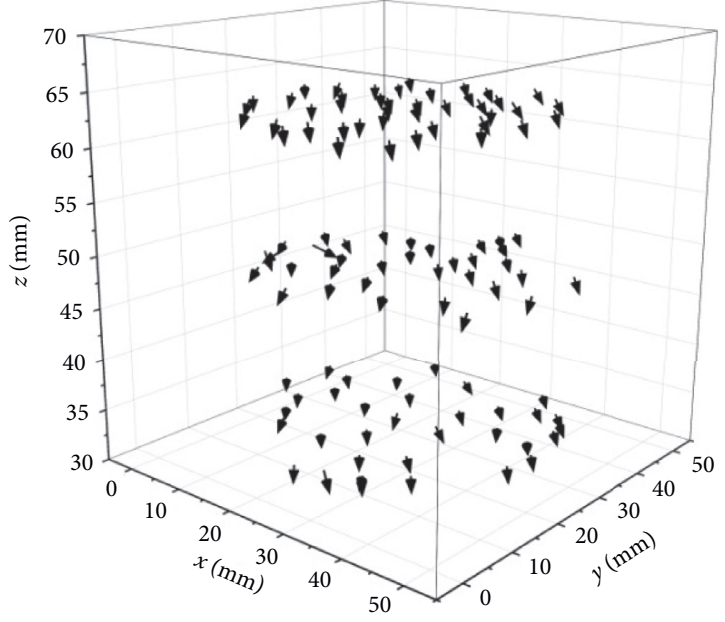

(b)

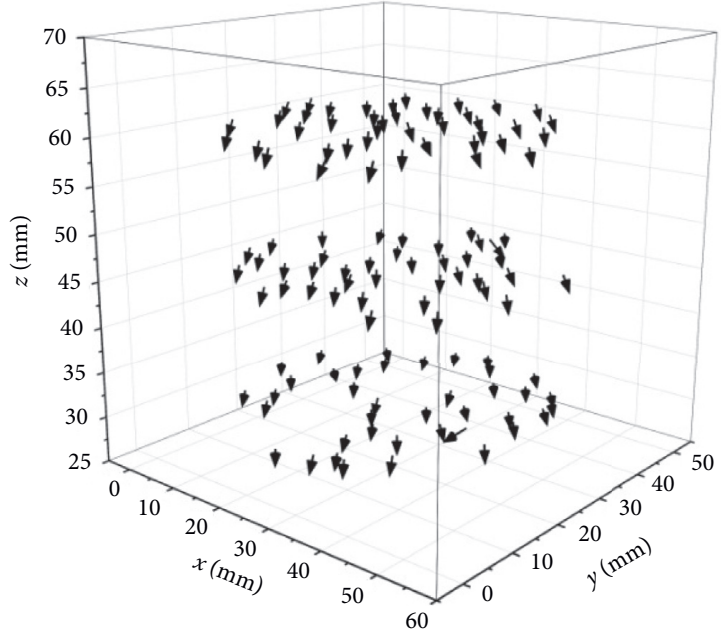

(d)

Figure 9: Continued. 


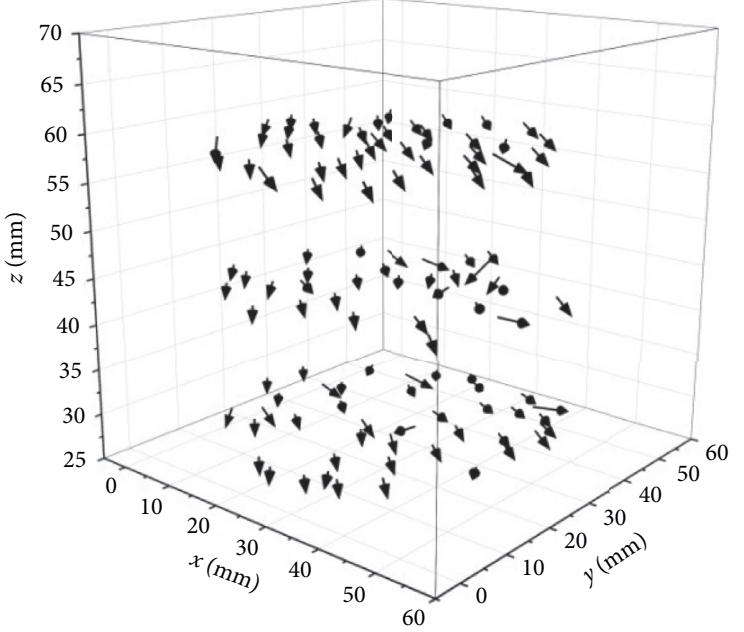

(e)

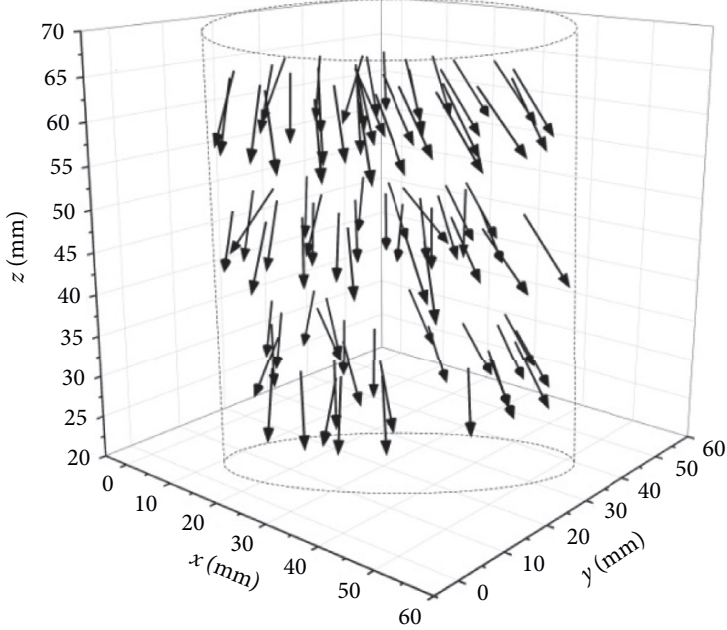

(f)

Figure 9: 3D displacement vectors of rock blocks during compression. (a) Axial strain: $0 \%$ to $1.480 \%$. (b) Axial strain: $1.480 \%$ to $3.083 \%$. (c) Axial strain: $3.083 \%$ to $4.012 \%$. (d) Axial strain: $4.012 \%$ to $6.012 \%$. (e) Axial strain: $6.012 \%$ to $8.032 \%$. (f) Axial strain: $0 \%$ to $8.032 \%$.
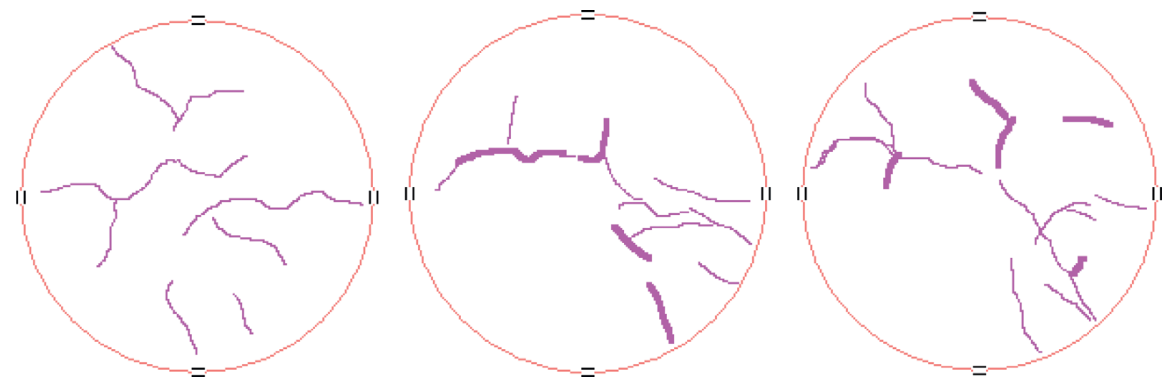

(a)
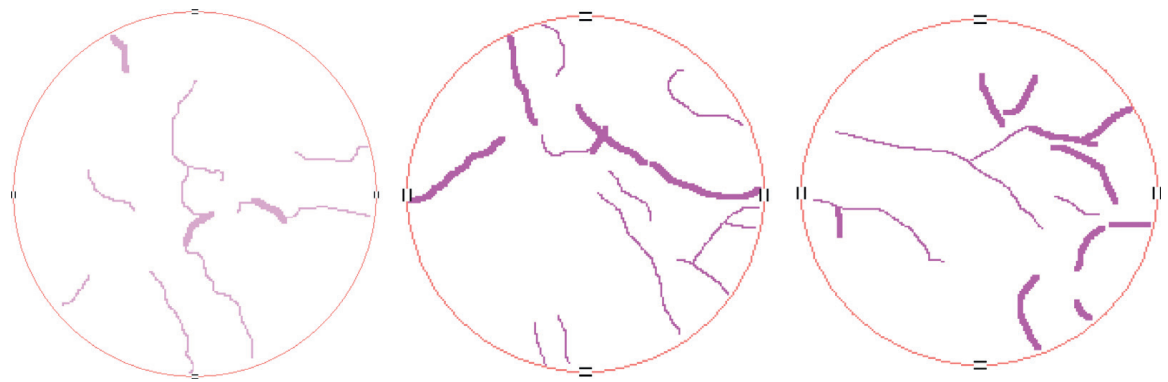

(b)
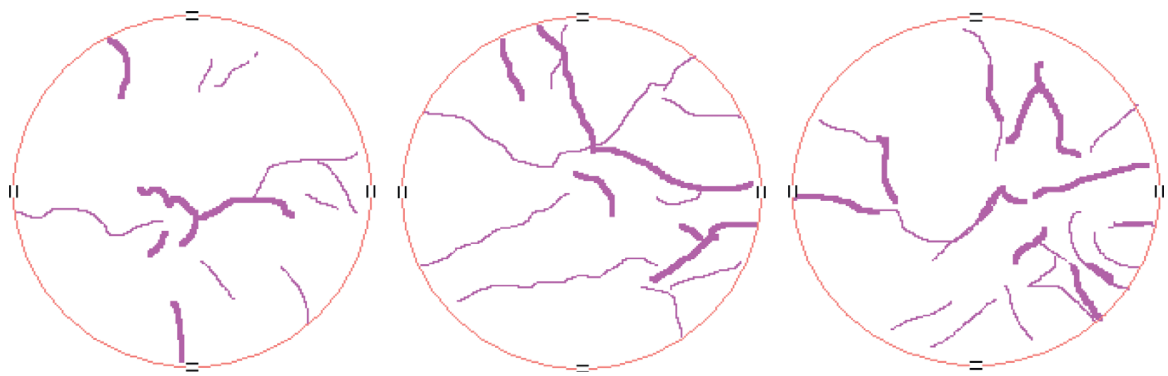

(c)

Figure 10: Continued. 

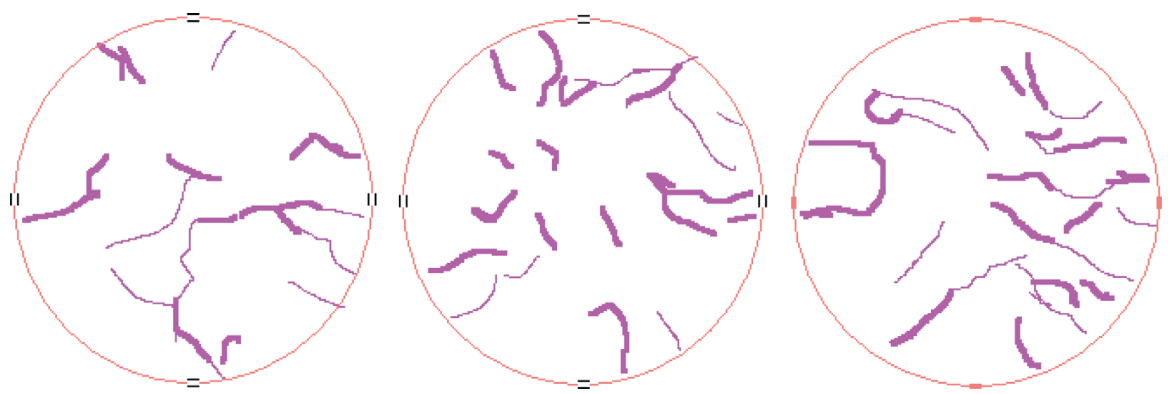

(d)
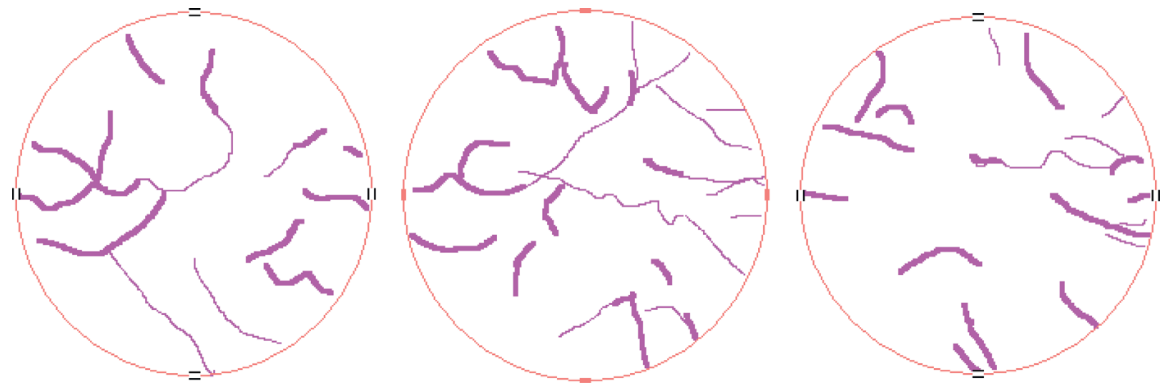

(e)

FIGURE 10: The cracks segmentation from the original CT slices at the five loading levels. (a) $\varepsilon=1.756 \%$. (b) $\varepsilon=3.106 \%$. (c) $\varepsilon=4.427 \%$. (d) $\varepsilon=6.649 \%$. (e) $\varepsilon=8.059 \%$.

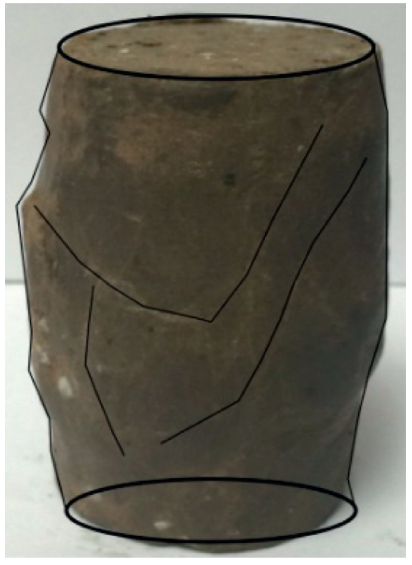

(a)

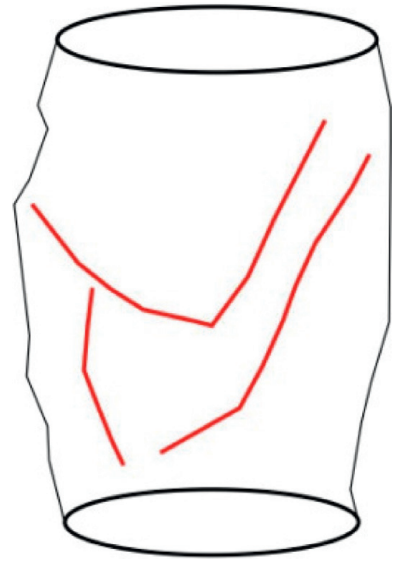

(e)

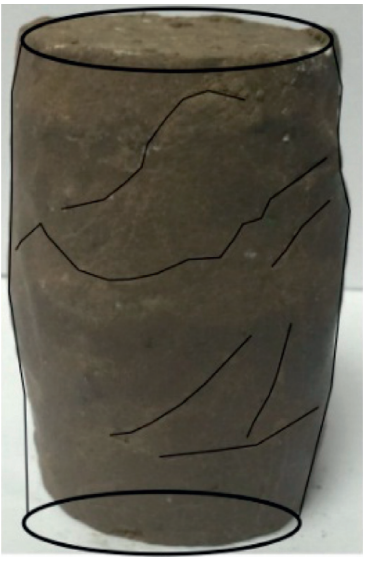

(b)

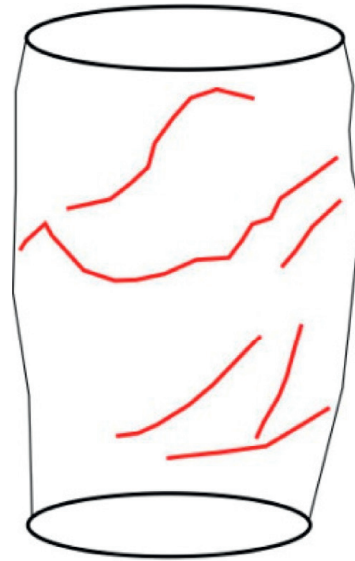

(f)

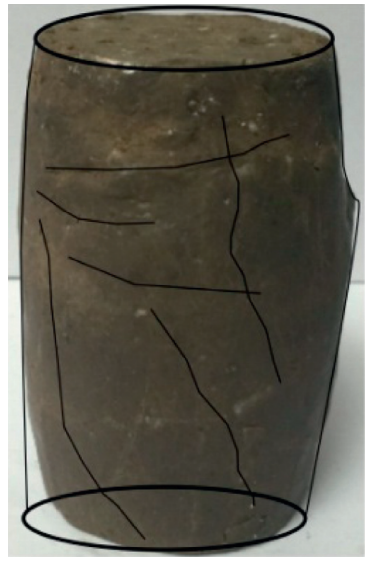

(c)

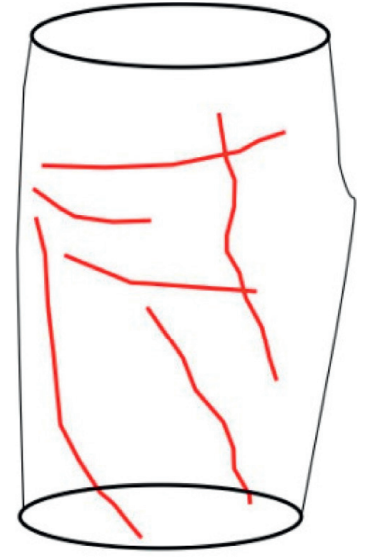

(g)

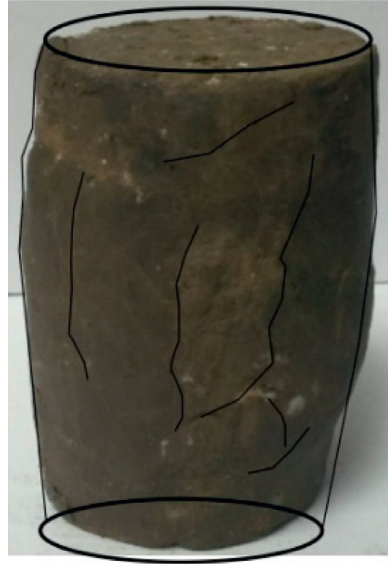

(d)

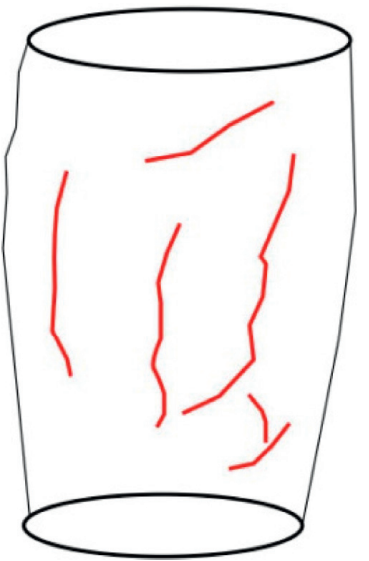

(h)

Figure 11: The failure morphology of the tested bimrock sample. (a) (d) Failure morphology, corresponding to the anterior, left, posterior, and right side of the sample. (e) (f) Crack sketch maps of the four sides. 
percentage is the most important factor resulting in the failure mechanism of bimrock. With increasing rock block percentage in bimrock, the failure pattern is from shear failure to bulging failure. For the bimrock sample with RBP of $40 \%$, the strain localization analysis in the above section indicates that the shear failure is not obvious for this sample; in other words, it is influenced by the distribution of localized bands, and the bulging deformation plays a dominant role. After the experiment, the sample was removed and we observed the macroscopic failure morphology by naked eyes; the sample was observed in four directions, as shown in Figure 11. From these results, it was determined that the localized bands propagated and coalesced in the soil matrix, and then the main failure plane formed. Shearing sliding occurs along the rock-soil interfaces and makes the formation of localized bands. Those bands are distributed relatively homogeneously inside the sample, which implies a bulging deformation pattern for this sample. The result further proves the reasonability of the displacement vector result. The accuracy of the rock block ID-tracking method can be acceptable since the obtained displacement is almost the same as the macroscopic failure morphology.

\section{Conclusions}

In order to investigate the geomechanical properties of bimrock, such as deformation and failure, more quantitative information about the strain field is required. In this work, an original experimental device has been designed for testing a bimrock sample at relatively low ambient pressures $(120 \mathrm{kPa})$, which allows for tomography imaging of the sample under deviatoric loading. A method called Block Tracking Movement has been proposed to monitor the displacement of rock bocks in the sample. Using this method, the 3D displacement vectors have been calculated, and the strain localization evolution during deformation has been discussed. The main conclusions can be drawn as follows:

(1) A proper method of image processing analysis called BTM method that can well track the non-linear movement of rock blocks and reflect the structural changes of localized bands is developed. During sample deformation, deformation evolution involving localization changes in bulk density can be indirectly probed by rock block movement from those CT images.

(2) Interactions among the soil and block components are the main reason resulting in the strain localization in bimrock. The morphology and distribution of the localized bands are influenced by the rock block in bimrock. Existence of rock blocks and their relative positions significantly alter the stress distribution in bimrock. The spatial kinematics of rock blocks promotes the strain localization and the forming of shear bands. Movement and rotation of the rock block also lead to the closure of existing cracks and the formation of new cracks.

(3) Cracks in the low-density region have been well extracted by using the trinarized images. The volumetric expansion behaviors of bimrock resulting from the appearance of cracks are investigated. The trajectory of localized bands is strongly related to the crack propagation path.

\section{Data Availability}

The experimental data used to support the findings of this study are included within the article.

\section{Conflicts of Interest}

The authors declare no conflicts of interest.

\section{Acknowledgments}

This study was supported by the China Geological Survey Project (No. DD20190318), Beijing Science and Technology Project (Z191100001419015), the Beijing Natural Science Foundation (82020033), and the Fundamental Research Funds for the Central Universities (FRF-TP-20-004A2).

\section{References}

[1] I. Vardoulakis, "Bifurcation analysis of the triaxial test on sand samples," Acta Mechanica, vol. 32, no. 1-3, pp. 35-54, 1979.

[2] I. Vardoulakis, M. Goldscheider, and G. Gudehus, "Formation of shear bands in sand bodies as a bifurcation problem," International Journal for Numerical and Analytical Methods in Geomechanics, vol. 2, no. 2, pp. 99-128, 1978.

[3] H. E. Read and G. A. Hegemier, "Strain softening of rock, soil and concrete-a review article," Mechanics of Materials, vol. 3, no. 4, pp. 271-294, 1984.

[4] A. W. Bishop and D. J. Henkel, "The Measurement of Soil Properties in the Triaxial test," Coefficient of Internal Friction, Cornell University, Ithaca, NY, USA, 1962.

[5] F. Tatsuoka, M. S. A. Siddiquee, and C. Park, "Modeling stress-strain relations of sand," Soils and Foundations, vol. 33, no. 2, pp. 60-81, 1993.

[6] T. Kodaka, Y. Higo, and T. Takyu, "Deformation and failure characteristics of rectangular clay specimens under threedimensional condition," in Proceedings of the International conference on Soil Mechanics and Geotechnical Engineering, vol. 1, pp. 167-170, Aa balkema Publishers, Tokyo, Japan, August 2001.

[7] R. L. Michalowski and L. Shi, "Deformation patterns of reinforced foundation sand at failure," Journal of Geotechnical and Geoenvironmental Engineering, vol. 129, no. 5, pp. 439449, 2003.

[8] M. Mokni and J. Desrues, "Strain localization measurements in undrained plane-strain biaxial tests on Hostun RF sand," Mechanics of Cohesive-Frictional Materials, vol. 4, no. 4, pp. 419-441, 1999.

[9] K. H. Roscoe, "The influence of strains in soil mechanics," Géotechnique, vol. 20, no. 2, pp. 129-170, 1970.

[10] J. Desrues and G. Viggiani, "Strain localization in sand: an overview of the experimental results obtained in Grenoble using stereophotogrammetry," International Journal for $\mathrm{Nu}$ merical and Analytical Methods in Geomechanics, vol. 28, no. 4, pp. 279-321, 2004.

[11] D. Liu, Z. Gu, R. Liang et al., "Impacts of pore-throat system on fractal characterization of tight sandstones," Geofluids, vol. 2020, no. 9, Article ID 4941501, 17 pages, 2020. 
[12] X. Wang, C. Liu, S. Chen, L. Chen, K. Li, and N. Liu, "Impact of coal sector's de-capacity policy on coal price," Applied Energy, vol. 265, p. 114802, 2020.

[13] J. Wang, Y. Zhang, Z. Qin, S. Song, and P. Lin, “Analysis method of water inrush for tunnels with damaged waterresisting rock mass based on finite element method-smooth particle hydrodynamics coupling," Computers and Geotechnics, vol. 126, p. 103725, 2020.

[14] J. Otani, T. Mukunoki, and Y. Obara, "Characterization of failure in sand under triaxial compression using an industrial X-ray CT scanner," International Journal of Physical Modelling in Geotechnics, vol. 2, no. 1, pp. 15-22, 2002.

[15] Y. Wang, W. K. Feng, and C. H. Li, "On anisotropic fracture and energy evolution of marble subjected to triaxial fatigue cyclic-confining pressure unloading conditions," International Journal of Fatigue, vol. 134, p. 105524, 2020.

[16] Y. Wang, S. Gao, D. Liu, and C. Li, "Anisotropic fatigue behaviour of interbeded marble subjected to uniaxial cyclic compressive loads," Fatigue \& Fracture of Engineering Materials \& Structures, vol. 43, no. 6, pp. 1170-1183, 2020.

[17] Y. Wang, W. K. Feng, H. J. Wang, C. H. Li, and Z. Q. Hou, "Rock bridge fracturing characteristics in granite induced by freeze-thaw and uniaxial deformation revealed by AE monitoring and post-test CT scanning," Cold Regions Science and Technology, vol. 177, 2020.

[18] K. A. Alshibli, S. Sture, N. C. Costes et al., "Assessment of localized deformations in sand using X-ray computed tomography," Geotechnical Testing Journal, vol. 23, no. 3, pp. 274-299, 2000.

[19] Y. Wang, S. H. Gao, C. H. Li, and J. Q. Han, "Energy dissipation and damage evolution for dynamic fracture of marble subjected to freeze-thaw and multiple level compressive fatigue loading," International Journal of Fatigue, vol. 142, 2021.

[20] E. Medley and E. S. Lindquist, "The engineering significance of the scale-independence of some Franciscan Melanges in California, USA," in Proceedings Of The 35th US Rock Mechanics Symposium, vol. 1, pp. 907-914, Balkema, Rotterdam, Netherlands, January 1995.

[21] N. Coli, P. Berry, and D. Boldini, "In situ non-conventional shear tests for the mechanical characterisation of a bimrock," International Journal of Rock Mechanics and Mining Sciences, vol. 48, no. 1, pp. 95-102, 2011.

[22] Y. Wang, C. H. Li, and Y. Z. Hu, "3D image visualization of meso-structural changes in a bimsoil under uniaxial compression using X-ray computed tomography (CT)," Engineering Geology, vol. 248, pp. 61-69, 2019.

[23] E. S. Lindquist, The Strength and Deformation Properties of Melange, University of California, Berkeley, CA, USA, 1995.

[24] Y. Wang, J. M. Que, C. Wang, and C. H. Li, "Threedimensional observations of meso-structural changes in bimsoil using X-ray computed tomography (CT) under triaxial compression," Construction and Building Materials, vol. 190, pp. 773-786, 2018.

[25] H.-Y. Zhang, W.-J. Xu, and Y.-Z. Yu, "Triaxial tests of soilrock mixtures with different rock block distributions," Soils and Foundations, vol. 56, no. 1, pp. 44-56, 2016.

[26] W. J. Xu, Q. Xu, and R. L. Hu, "Study on the shear strength of soil-rock mixture by large scale direct shear test," International Journal of Rock Mechanics and Mining Sciences, vol. 45, pp. 1235-1247, 2011.

[27] L. E. Vallejo and R. Mawby, "Porosity influence on the shear strength of granular material-clay mixtures," Engineering Geology, vol. 58, no. 2, pp. 125-136, 2000.
[28] Y. Wang, C. H. Li, and Y. Z. Hu, "Use of X-ray computed tomography to investigate the effect of rock blocks on mesostructural changes in soil-rock mixture under triaxial deformation," Construction and Building Materials, vol. 164, pp. 386-399, 2018.

[29] Y. Wang, X. Li, B. Zheng, B. Zhang, J. M. He, and S. D. Li, "Macro-meso failure mechanism of soil-rock mixture at medium strain rates," Géotechnique Letters, vol. 6, no. 1, pp. 28-33, 2016.

[30] S. M. Springman, C. Jommi, and P. Teysseire, "Instabilities on moraine slopes induced by loss of suction: a case history," Géotechnique, vol. 53, no. 1, pp. 3-10, 2003.

[31] Y. Wang and X. Li, "Research on damage cracking for rock and soil aggregate using calculation meso-mechanics," Chinese Journal of Rock Mechanics and Engineering, vol. 33, no. 2, pp. 4020-4031, 2014.

[32] W.-J. Xu, S. Wang, H.-Y. Zhang, and Z.-L. Zhang, "Discrete element modelling of a soil-rock mixture used in an embankment dam," International Journal of Rock Mechanics and Mining Sciences, vol. 86, pp. 141-156, 2016.

[33] Y. Wang, X. Li, and Y.-F. Wu, "Damage evolution analysis of SRM under compression using X-ray tomography and numerical simulation," European Journal of Environmental and Civil Engineering, vol. 19, no. 4, pp. 400-417, 2015.

[34] Y. Wang, C.-H. Li, J.-Q. Han J, and H.-J. Wang, "Mechanical behaviours of granite containing two flaws under uniaxial increasing amplitude fatigue loading conditions: an insight into fracture evolution analyses," Fatigue \& Fracture of Engineering Materials \& Structures, vol. 43, pp. 1-16, 2020.

[35] Y. Wang, D. Q. Liu, J.-Q. Han, C. H. Li, and H. Liu, "Effect of fatigue loading-confining stress unloading rate on marble mechanical behaviors: an insight into fracture evolution analyses," Journal of Rock Mechanics and Geotechnical Engineering, vol. 34, 2020.

[36] B. Chen, S.-C. Zhang, Y.-Y. Li, Z. K. Li, and H. J. Zhou, "Physical simulation study of crack propagation and instability information discrimination of rock-like materials with faults," Arabian Journal of Geosciences, vol. 18, no. 13, pp. 1-13, 2020.

[37] C. Zhu, Z. G. Tao, S. Yang, and S. Zhao, "V shaped gully method for controlling rockfall of high-steep slope in China," Bulletin of Engineering Geology and the Environment, vol. 78, no. 4, pp. 2731-2747, 2019.

[38] Y. Higo, F. Oka, T. Sato, Y. Matsushima, and S. Kimoto, "Investigation of localized deformation in partially saturated sand under triaxial compression using microfocus X-ray CT with digital image correlation," Soils and Foundations, vol. 53, no. 2, pp. 181-198, 2013.

[39] J.-T. Chen, J.-H. Zhao, S. C. Zhang, Y. Zhang, F. Yang, and M. Li, "An experimental and analytical research on the evolution of mining cracks in deep floor rock mass," Pure and Applied Geophysics, vol. 15, 2020.

[40] G. Viggiani, N. Lenoir, and P. Bésuelle, "X-ray microtomography for studying localized deformation in finegrained geomaterials under triaxial compression," Comptes Rendus Mécanique, vol. 332, no. 10, pp. 819-826, 2014.

[41] S. Akin and A. R. Kovscek, "Computed tomography in petroleum engineering research," Geological Society, London, Special Publications, vol. 215, no. 1, pp. 23-38, 2003. 